\title{
Cultural SIMILARITY AND INTERNATIONAL TRADE IN A PANEL OF NATIONS
}

\author{
Eui-Gak Hwang \\ Department of Economics, Korea University, Korea \\ Rongxing Guo \\ Regional Science Association, Peking University, China
}

\begin{abstract}
Using a gravity model and the data of a panel of eight nations, we present evidence that supports the views that geographical influence on trade had increased from 1985 to 1997. In both years, linguistic influence on trade is found to exist in export but not in import. The estimated results show a positive relation between religious similarity and international trade for the year 1985 but not for the year 1997. However, there is an indication that, for 1997, the religious dissimilarity tends to discourage international trade with low-income countries and regions and to encourage international trade with high-income countries. We also find that, for low-income trade partners, religious dissimilarity retards imports more than exports; by contrast, for high-income trade partners, it encourages exports more than imports.
\end{abstract}

JEL F11, Z1

\section{1}

\section{Introduction}

To date, studies of the determinants of international trade have been controversial, or at least incomplete. According to the Heckscher-Ohlin Theorem (see Heckscher, 1919 and Ohlin, 1933), production depends on two factors, capital and labour, and countries with dissimilar levels of per capita income, or, more precisely, dissimilar capital/labour ratios, will trade more than countries with equal levels. However, the results from a number of empirical studies indicate that the inclusion of income level as a determinant of trade does contradict the preconditions of traditional $\mathrm{H}$ $\mathrm{O}$ theory on trade (see, for example, Linder, 1961 and Deardorff, 1997). To clear this confusion, economists have put forward several new theories that model international trade according to economies of scale, imperfection and cross-national differences in technological changes, among other criteria (see, for example,
Markusen, 1986, Helpman, 1987 and Krugman, 1995).

In general, these past studies raise more questions than they answer. For example, no observable tendency has been detected for the effect of geographical proximity to decrease over time. Rather, the effect seems to have increased, for example over the periods of 19501988 (Boisso \& Ferrantino, 1997) and 19651992 (Frankel et al., 1997). In their analysis of the negative correlation between distance and interdependence between sovereign countries, Frankel et al. (1994) obtain from data for the 1980s only slightly larger coefficients (around 0.5 to 0.6 ) on distance compared with Eichengreen and Irwin's 1995 estimates (around 0.3 to 0.6 ) based on data for the 1930 s. Clearly both studies provide no evidence that declining transportation cost has had an increasingly important influence on patterns of trade. We suspect that some factors that either resist or aid international trade might be missing from these and other existing empirical studies on trade. 
Since the 1990s, several quantitative studies on the role of cultural factors that influence international trade have been conducted (see, for example, Havrylyshyn \& Pritchett, 1991; Foroutan \& Pritchett, 1993; Frankel \& Wei, 1995, Table 5; Frankel et al., 1997; and Rauch, 1999). These studies, in which linguistic links are used as explanatory variables, consistently show that the estimated coefficients for linguistic similarity among trade partners exhibit a trend of cointegration in the post-war period, or in other words, provide possible evidence of increased language (cultural) barriers to trade. However, cultural variables have been highly simplified in these studies, probably because the cultural factors are only treated as complementary variables to other more important determinants of trade. For example, the linguistic links between countries are treated in some of the above studies as a dummy variable. As most countries show linguistic diversity, the international (or interregional) linguistic links should not be simply expressed as in some studies by the numbers " 1 " (for countries who share a common language) and "0" (for countries who do not $)^{1}$. Last but not least, the existing literature omits another cultural variable, religion, which could at least in some cases play a more important role in economic affairs than the linguistic variable (Guo \& Hwang, 2002).

This paper has the following structure. In Section 2, a modified form of the gravity model of trade is constructed taking into account cultural factors. In order to compare the estimated coefficients for the Cold War and post-Cold War periods, we select two years, 1985 and 1997, with the panel data of eight countries (Brazil, China, Democratic Republic of Congo (or Zaire for 1985), France, India, Japan, Saudi Arabia and the United States). We use a comprehensive measure of the cultural links between any pair of economies so as to generate the data on cultural variables. Although the components of culture have been variously defined, we focus on only two elements, language and religion. Of course, our discussion of these cultural elements is not definitive and perhaps would not satisfy anthropologists. These two factors were chosen because "language" is the only effective tool of communication among traders and that "religion" is one of the most important representative characteristics of cultural diversity.

Using the gravity model and the panel data, section 4 tests the effects of cultural influences on international trade. Although only eight countries are selected for this study, they encompass the major part of the world economy and population. What is more, each of these countries represents a major linguistic and/or religious cohort in the culturally diversified world. The data of the panel of countries analyzed in this study is very selective, and different from the data set used by Frankel et al. (1996) and Rauch (1999), who analyzed crossnational trade relations among 63 countries $^{2}$. The reasons for our choice of the eight countries out of the possible 198 countries data set are the following. First, we intend to present the full picture of international trade as far as possible (not just of the major trade partners only). Second, our panel data that include only eight country pairs will make the preparation of the cross-national data on linguistic and religious links much easier ${ }^{3}$.

Based on the estimated results for section 4, the last section concludes with a brief discussion of the policy implications as well as with recommendations for managers and policymakers. Some remaining problems and further research areas are also suggested in this section.

2

\section{Methodology}

In quantitative studies of international trade, the gravity model is one of the most common tools used by economists ${ }^{4}$. The most classic and extensive early application of the model is that of Linnemann (1966), who continued his work first reported in Tinbergen (1962) and then Pöyhönen (1963). The most recent work on the application of the model to international trade is by Frankel et al. (1997) and Rauch (1999), among others. Generally, a gravity model assumes that the size of bilateral trade between any two countries depends on both the product 
of the economic sizes of the countries and the distance between them. In addition to "distance', "adjacency" (that is, the common land border shared by a country pair) also influences international trade.

In order to test the effects of the various cultural variables on trade, we introduce controls for other political and social variables. Thus the study focuses on the two chosen cultural variables, represented by linguistic and religious similarities. As a control for the countries" propensity to trade, we use a country dummy for each country. The basic form of the gravity model to be used in our empirical analysis is as follows:

$\ln \left(\mathrm{TRADE}_{i j}+1\right)=\alpha_{0}+\alpha_{1} \ln \left(\mathrm{GNP}_{i} \mathrm{GNP}_{j}\right)+$ $\alpha_{2} \operatorname{lnDISTANCE}_{i j}+\alpha_{3}$ ADJACENCE $_{i j}+$ $\alpha_{4}$ LANGUAGE $_{i j}+\alpha_{5}$ RELIGION $_{i j}+$ $\alpha_{6}$ Countries

In Equation 1, "ln" represents natural logarithm and TRADE denotes nominal bilateral trade between countries (regions) $i$ and $j$ (in thousand US dollars). In order to make the natural logarithm of TRADE become mathematically meaningful when $\mathrm{TRADE}=0$, we use $\ln ($ TRADE +1$)$ to approximately denote $\ln$ (TRADE). This seems to be reasonable since the size of TRADE (measured in thousand US dollars ) is, if not zero, always far larger than 1 . $\mathrm{GNP}_{i} \mathrm{GNP}_{j}$ is the product of nominal GNPs of countries (regions) $i$ and $j$ (all in thousand US dollars). DISTANCE represents the distance between the geographical centers of gravity of countries (regions) $i$ and $j$ in kilometers, and ADJACENCE is a dummy variable, which takes the value of " 1 " for countries (regions) $i$ and $j$ if they have a common border and " 0 " for if they do not. Extrapolating from previous studies, we expect the estimated coefficients for these variables to follow: $\alpha_{1}>0, \alpha_{2}<0$, and $\alpha_{3}>0$.

We are most interested in the cultural factors that resist or aid international trade. To go further, we use LANGUAGE and RELIGION to express the extents to which countries (regions) $i$ and $j$ are linguistically and religiously linked to one another. Some previous studies, such as those by Frankel et al. (1993 \& 1997), use dummies for "membership" in the geo- graphical areas such as East Asia or Western Hemisphere. Including these dummy variables, as argued by Rauch (1999, fn. 6), could shrink the estimated coefficients on 'distance'. In equation (1), therefore, we attempt first to exclude the DISTANCE and ADJACENCE variables because they may compound the problem of interpretation that will be presented by the cultural variables employed.

In this study, we are most interested in the cultural factors if they encourage or restrict international trade. The question is how to measure cultural similarity most accurately, since there are several methods of measurement. The simplest method is to use a dummy index: that is, " 1 " for countries (regions) that are culturally linked with one another and " 0 " for countries that are not. However, this approach is too simplified to precisely express how and the extent to which two countries (or cohort groups) are culturally connected, particularly given that the countries concerned are culturally diverse in the real world. Therefore, in our study, we use a comprehensive method for measuring cultural similarity. Suppose that the population ratios of the $\mathrm{N}$ cultural groups are expressed by $\left(\mathrm{x}_{1}, \mathrm{x}_{2}\right.$, ....and $\left.\mathrm{x}_{\mathrm{n}}\right)$ and $\left(\mathrm{y}_{1}, \mathrm{y}_{2} \ldots\right.$ and $\left.\mathrm{y}_{\mathrm{n}}\right)$ for countries $\mathrm{X}$ and $\mathrm{Y}$ respectively. For all $\mathrm{i}, \mathrm{x}_{\mathrm{i}}$ and $\mathrm{y}_{\mathrm{i}}$ (where $x_{i} \geq 0$ and $y i \geq 0$ ) belong to the same cultural group. Mathematically, the cultural similarity between the two countries (regions), similarity (X, Y), is measured according to this formula:

similarity $(\mathrm{X}, \mathrm{Y})=\Sigma_{\mathrm{i}} \min \left(\mathrm{x}_{\mathrm{i}}, \mathrm{y}_{\mathrm{i}}\right)$,

where "min" denotes the minimization of the variables in parenthesis. The value of similarity does of course range between " 0 " and " 1 ". If similarity $=1$, the two countries (regions) have the same cultural structure, that is, for all $i, x_{i}=$ $y_{i}$. And when similarity $=0$, the two countries do not have any cultural links. In between 0 and 1 , the greater the value for similarity is, the more similar the two countries (regions) are. (For further details, see Guo, 2004).

Technically, if one or more cultural variables is statistically insignificant in equation 1 , there might possibily be a non-linear relationship between international trade and cultural similarity. To investigate the non-linear 
relationship, we add a new variable, $\ln \left(\mathrm{GNPPC}_{j}\right)$, where $\ln \left(\mathrm{GNPPC}_{j}\right)$ is the natural $\log$ of the per capita GNP (in nominal US dollars) of the country (region) $j$. We can take the RELIGION variable as an example: the effect of the RELIGION score on international trade is taken as depending on the level of economic development, reflected by per capita GNP. The RELIGION variable is now entered into the gravity model of trade, both linearly and as a product with the natural log of per capita GNP. This yields another form of the gravity model $^{5}$ :

$\ln \left(\mathrm{TRADE}_{i j}+1\right)=\beta_{0}+\beta_{1} \ln \left(\mathrm{GNP}_{i} \mathrm{GNP}_{j}\right)+$ $\beta_{2} \operatorname{lnDISTANCE}{ }_{i j}+\beta_{3}$ ADJACENCE $_{i j}+$ $\beta_{4}$ LANGUAGE $_{i j}+\beta_{5}$ RELIGION $_{i j}+$ $\beta_{6}$ RELIGION $_{i j} \ln \left(\right.$ GNPPC $\left._{j}\right)+\beta_{7}$ Countries $(3)$

In equation 3 , if the estimated coefficients for RELIGION $_{i j}\left(\beta_{5}\right)$ and RELIGION $N_{i j}$ ln $\operatorname{~GNPPC}_{j}\left(\beta_{6}\right)$ have different signs (that is, $\beta_{5}>0$ and $\beta_{6}<0$; or $\beta_{5}<0$ and $\beta_{5}>0$ ) and are statistically significant, we obtain a breakpoint value $\left(\mathrm{GNPPC}^{*}\right)$ by letting the first-order differentials of the dependent variable $\left(\ln \left(\mathrm{TRADE}_{i j}+1\right)\right.$ with respect to RELIGION be zero, that is, $\mathrm{GNPPC}^{*}=\exp \left(-\beta_{5} \beta_{6}\right)$. Specifically, as when $\beta_{5}>0$ and $\beta_{6}<0$, the effect of religious similarity on international trade is positive if the income level of trade partner $j$ $\left(\mathrm{GNPPC}_{j}\right)$ is less than GNPPC, or negative if the income level is more than this.

To verify this result, the trade model can be reestimated with the RELIGION scores allowed to have two separate coefficients, as illustrated by the following:

$$
\begin{aligned}
& \ln \left(\text { TRADE }_{i j}+1\right)=\gamma_{0}+\gamma_{1} \ln \left(\operatorname{GNP}_{i} \text { GNP }_{j}\right)+ \\
& \gamma_{2} \operatorname{lnDISTANCE}{ }_{i j}+\gamma_{3} \text { DDJACENCE }_{i j}+ \\
& \gamma_{4} \text { LANGUAGE }_{i j}+\gamma_{5} \text { RELIGION }_{i j} \text { if } \\
& \text { GNPPC }_{j}<\text { GNPPC }_{5} \gamma_{6} \text { RELIGION }_{i j}[\text { if } \\
& \text { GNPPC } \left._{j}>\text { GNPPC }^{*}\right]+\gamma_{7} \text { Countries }
\end{aligned}
$$

Obviously, if the estimated coefficients for RELIGION $_{i j}\left(\beta_{5}\right)$ and RELIGION $\ln \left(\operatorname{GNPPC}_{j}\left(\beta_{6}\right)\right.$ are estimated as significant by equation 3 , the two separate coefficients for RELIGION $_{i j}$ (that is, $g_{5}$ and $g_{6}$ in Equation 4) are expected to have the following signs: (1) $\gamma_{5}>0$ and $\gamma_{6}<0$ if $\gamma_{5}>0$ and $\gamma_{6}<0$; (2) $\gamma_{5}<0$ and $\gamma_{6}>0$ if $\beta_{5}<0$ and $\beta_{5}>0$.

\section{3 \\ Data}

To quantitatively investigate cultural influences on international trade during the Cold War and the post-Cold War periods, we will use panel data for two years, 1985 and 1997, for Brazil, China, the Democratic Republic of Congo (or Zaire for 1985), France, India, Japan, Saudi Arabia and the United States. These eight countries are chosen not only because they encompassed most of the world economy and population, but also because they represent the major linguistic and/or religious groups of the world $^{6}$. In sum, the languages to be considered are Amharic, Arabic, Armenian, Bengali, Chinese, Czech, Danish, Dutch, English, Finnish, French, Greek, Hebrew, Hindi, Hungarian, Italian, Japanese, Kazak, Korean, Kyrgyz, Miao, Mongol, Norwegian, Polish, Portuguese, Punjabi, Romanian, Samoan, Serbo-Croatian, Slovak, Spanish, Swedish, Tajik, Thai, Turkish, Uighur, Ukrainian, Vietnamese, Yao and Yiddish. The religions are Christianity, Orthodox Judaism, Islam, Buddhism, Chinese folk-religion (a mixture of Confucianism and Taoism, which still has followers in China and some Southeast Asian countries), Hinduism, Sikhism and Bahai. The distributions of the major linguistic and religious groups in the populations of the eight countries are listed in Table $1^{7}$. 
Table 1a

Major linguistic groups, 1985 and 1997, by country

\begin{tabular}{|l|r|r|r|r|r|r|r|r|r|r|r|r|r|r|}
\hline Country & \multicolumn{2}{|c|}{ Arabic } & \multicolumn{2}{c|}{ Chinese } & \multicolumn{2}{c|}{ English } & \multicolumn{2}{c|}{ French } & \multicolumn{2}{c|}{ Greek } & \multicolumn{2}{c|}{ Hindi } & \multicolumn{2}{c|}{ Italian } \\
\hline & $\mathbf{1 9 8 5}$ & $\mathbf{1 9 9 7}$ & $\mathbf{1 9 8 5}$ & $\mathbf{1 9 9 7}$ & $\mathbf{1 9 8 5}$ & $\mathbf{1 9 9 7}$ & $\mathbf{1 9 8 5}$ & $\mathbf{1 9 9 7}$ & $\mathbf{1 9 8 5}$ & $\mathbf{1 9 9 7}$ & $\mathbf{1 9 8 5}$ & $\mathbf{1 9 9 7}$ & $\mathbf{1 9 8 5}$ & $\mathbf{1 9 9 7}$ \\
\hline Brazil & 0.00 & 0.00 & 0.00 & 0.00 & 0.00 & 0.00 & 0.00 & 0.00 & 0.00 & 0.00 & 0.00 & 0.00 & 0.00 & 0.42 \\
\hline China & 0.00 & 0.00 & $\mathbf{8 8 . 6 5}$ & 91.96 & 0.00 & 0.00 & 0.00 & 0.00 & 0.00 & 0.00 & 0.00 & 0.00 & 0.00 & 0.00 \\
\hline Congo, Dem. & 0.00 & 0.00 & 0.00 & 0.00 & 0.00 & 0.00 & 0.00 & 3.42 & 0.00 & 0.00 & 0.00 & 0.00 & 0.00 & 0.00 \\
\hline France & 2.63 & 2.53 & 0.00 & 0.00 & 0.00 & 0.14 & 81.48 & 93.68 & 0.00 & 0.00 & 0.00 & 0.00 & 0.00 & 0.44 \\
\hline India & 0.00 & 0.00 & 0.00 & 0.00 & 0.00 & 3.58 & 0.00 & 0.00 & 0.00 & 0.00 & 28.08 & 50.22 & 0.00 & 0.00 \\
\hline Japan & 0.00 & 0.00 & 0.00 & 0.17 & 0.00 & 0.06 & 0.00 & 0.00 & 0.00 & 0.00 & 0.00 & 0.00 & 0.00 & 0.00 \\
\hline Saudi Arabia & 97.00 & 95.02 & 0.00 & 0.00 & 0.00 & 0.00 & 0.00 & 0.00 & 0.00 & 0.00 & 0.00 & 0.00 & 0.00 & 0.00 \\
\hline United States & 0.00 & 0.14 & 0.29 & 0.51 & 88.99 & 87.53 & 0.73 & 0.74 & 0.18 & 0.15 & 0.00 & 0.13 & 0.74 & 0.51 \\
\hline
\end{tabular}

\begin{tabular}{|c|c|c|c|c|c|c|c|c|c|c|c|c|c|c|}
\hline \multirow[t]{2}{*}{ Country } & \multicolumn{2}{|c|}{ Japanese } & \multicolumn{2}{|c|}{ Korean } & \multicolumn{2}{|c|}{ Polish } & \multicolumn{2}{|c|}{ Portuguese } & \multicolumn{2}{|c|}{ Spanish } & \multicolumn{2}{|c|}{ Turkish } & \multicolumn{2}{|c|}{ Ukrainian } \\
\hline & 1985 & 1997 & 1985 & 1997 & 1985 & 1997 & 1985 & 1997 & 1985 & 1997 & 1985 & 1997 & 1985 & 1997 \\
\hline Brazil & 0.00 & 0.38 & 0.00 & 0.00 & 0.00 & 0.00 & 98.97 & 97.55 & 0.00 & 0.00 & 0.00 & 0.00 & 0.00 & 0.00 \\
\hline China & 0.00 & 0.00 & 0.17 & 0.17 & 0.00 & 0.00 & 0.00 & 0.00 & 0.00 & 0.00 & 0.00 & 0.00 & 0.00 & 0.00 \\
\hline Congo, Dem. & 0.00 & 0.00 & 0.00 & 0.00 & 0.00 & 0.00 & 0.00 & 0.00 & 0.00 & 0.00 & 0.00 & 0.00 & 0.00 & 0.00 \\
\hline France & 0.00 & 0.00 & 0.00 & 0.00 & 0.64 & 0.09 & 0.00 & 1.14 & 0.00 & 0.38 & 0.00 & 0.34 & 0.00 & 0.00 \\
\hline India & 0.00 & 0.00 & 0.00 & 0.00 & 0.00 & 0.00 & 0.00 & 0.00 & 0.00 & 0.00 & 0.00 & 0.00 & 0.00 & 0.00 \\
\hline Japan & 99.43 & 99.09 & 0.47 & 0.53 & 0.00 & 0.00 & 0.00 & 0.00 & 0.00 & 0.00 & 0.00 & 0.00 & 0.00 & 0.00 \\
\hline Saudi Arabia & 0.00 & 0.00 & 0.00 & 0.00 & 0.00 & 0.00 & 0.00 & 0.00 & 0.00 & 0.00 & 0.00 & 0.00 & 0.00 & 0.00 \\
\hline United States & 0.15 & 0.17 & 0.12 & 0.25 & 0.37 & 0.28 & 0.17 & 0.17 & 5.33 & 6.78 & 0.00 & 0.02 & 0.00 & 0.04 \\
\hline
\end{tabular}

Source: Calculated by the authors based on Britannica Book of the Year (1986 and 1998).

Table $\mathbf{1 b}$

Major religious groups, 1985 and 1997, by country

\begin{tabular}{|c|c|c|c|c|c|c|c|c|c|c|c|c|c|c|c|c|c|c|}
\hline Country & \multicolumn{2}{|c|}{ Christian } & \multicolumn{2}{|c|}{ Orthodox } & \multicolumn{2}{|c|}{ Jewish } & \multicolumn{2}{|c|}{ Muslim } & \multicolumn{2}{|c|}{ Buddhist } & \multicolumn{2}{|c|}{ Hindu } & \multicolumn{2}{|c|}{ Sikh } & \multicolumn{2}{|c|}{ Bahai } & \multicolumn{2}{|c|}{$\begin{array}{l}\text { Chinese } \\
\text { folk- } \\
\text { religion }\end{array}$} \\
\hline Brazil & 95.49 & 93.90 & 0.00 & 0.00 & 0.00 & 0.00 & 0.00 & 0.00 & 0.00 & 0.00 & 0.00 & 0.00 & 0.00 & 0.00 & 0.00 & 0.00 & 0.00 & 0.00 \\
\hline $\begin{array}{l}\text { Congo, } \\
\text { Dem. }\end{array}$ & 85.99 & 77.43 & 0.00 & 0.00 & 0.00 & 0.00 & 1.39 & 0.00 & 0.00 & 0.00 & 0.00 & 0.00 & 0.00 & 0.00 & 0.00 & 0.00 & 0.00 & 0.00 \\
\hline France & 78.06 & 76.40 & 0.00 & 0.00 & 1.04 & 0.00 & 5.49 & 3.00 & 0.00 & 0.00 & 0.00 & 0.00 & 0.00 & 0.00 & 0.00 & 0.00 & 0.00 & 0.00 \\
\hline India & 3.51 & 2.60 & 0.00 & 0.00 & 0.00 & 0.00 & 11.05 & 11.20 & 0.72 & 0.70 & 82.70 & 80.26 & 1.90 & 1.96 & 0.00 & 0.00 & 0.00 & 0.00 \\
\hline $\begin{array}{l}\text { United } \\
\text { States }\end{array}$ & 81.24 & 84.25 & 2.37 & 2.44 & 2.32 & 3.55 & 1.58 & 0.00 & 0.78 & 0.00 & 0.00 & 0.34 & 0.00 & 0.08 & 0.00 & 0.29 & 0.00 & 0.00 \\
\hline
\end{tabular}


From these figures we can set up the model described in Section 3.1 separately for the years 1997 (the latest year when the research was conducted) and 1985 (a year used to denote the Cold war period). This enables us to check that the results are not artefacts of any particular time period and to allow for changes in coefficients, especially on DISTANCE, LANGUAGE and RELIGION, that might have taken place due to changes in transportation and communication technology. In selecting the religions for measurement of RELIGION scores, such religions as "folk religion" (but "Chinese folk-religion" is an exception), "traditional religion', "atheism" and "non-religion" are removed from Equation 4. This is because of concerns that these religions should not be scored as "common" in our measure of religious similarity. For example, "traditional or folk religionists" from one nation, say, Togo, and "traditional or folk religionists" from the other nation, say, China, do not have enough common religious ground to trust each other.

Therefore, the sample of countries (regions), as listed in Table 2, includes 162 countries for 1985 and 195 for 1997. Data sources are the following: (1) the IMF (2003) for TRADE; (2) the World Bank (1986 and 1999) and UN (1986) for GNP; (3) calculations by the authors based on the World Atlas (1994) for DISTANCE and ADJACENCE; and (4) calculations based on equation 4 and Britannica Book (1986 and 1998) for LANGUAGE and RELIGION ${ }^{8}$.

\section{Table 2}

List of the trade partners included in the panel

1985: Algeria; Angola; Antigua \& Barbuda; Argentina; Australia; Austria; Bahamas; Bahrain; Bangladesh; Barbados; Belgium; Belize; Benin; Bermuda; Bhutan; Bolivia; Botswana; Brazil; Brunei; Bulgaria; Burkina Faso; Burundi; Cameroon; Canada; Cape Verde; Central Africa Rep.; Chad; Chile; China; Colombia; Comoros; Congo, Dem.; Congo, Rep.; Costa Rica; Cuba; Cyprus; Czechoslovakia; Denmark; Dominica; Dominican Rep.; Ecuador; Egypt, Arab Rep.; El Salvador; Equatorial Guinea; Ethiopia; Faeroe Islands; Fiji; Finland; France; Gabon; Gambia, The; Germany; Germany Dem. Rep.; Ghana; Greece; Greenland; Grenada; Guadeloupe; Guatemala; Guinea; Guinea-Bissau; Guyana; Haiti; Honduras; Hong Kong; Hungary; Iceland; India; Indonesia; Iran, Islamic Rep.; Iraq; Ireland; Israel; Italy; Jamaica; Japan; Jordan; Kenya; Kiribati; Korea, Dem. Rep.; Korea, Rep. of; Kuwait; Lao PDR; Lesotho; Liberia; Libya; Luxembourg; Madagascar; Malawi; Malaysia; Maldives; Mali; Malta; Martinique; Mauritania; Mauritius; Mexico; Morocco; Mozambique; Myanmar; Nepal; Netherlands; New Zealand; Nicaragua; Niger; Nigeria; Norway; Oman; Pakistan; Panama; Papua New Guinea; Paraguay; Peru; Philippines; Poland; Portugal; Puerto Rico; Qatar; Reunion; Romania; Rwanda; Sao Tome \& Principe; Saudi Arabia; Senegal; Seychelles; Sierra Leone; Singapore; Solomon Islands; Somalia; South Africa; Spain; Sri Lanka; St. Lucia; St. Vincent; Sudan; Suriname; Swaziland; Sweden; Switzerland; Syrian Arab Rep.; Tanzania; Thailand; Togo; Tonga; Trinidad \&Tobago; Tunisia; Turkey; Uganda; United Arab Emirates; United kingdom; United States; Uruguay; USSR; Vanuatu; Venezuela; Virgin Island (U.S.); Western Samoa; Yemen Arab Rep.; Yemen, PDR; Yugoslavia; Zambia; Zimbabwe.

1997: Afghanistan; Albania; Algeria; Andorra; Angola; Antigua and Barbuda; Argentina; Armenia; Australia; Austria; Azerbaijan; Bahamas; Bahrain; Bangladesh; Barbados; Belarus; Belgium; Belize; Benin; Bhutan; Bolivia; Bosnia and Herzegovina; Botswana; Brazil; Brunei Darussalam; Bulgaria; Burkina Faso; Burundi; Cambodia; Cameroon; Canada; Cape Verde; Central African Rep.; Chad; Chile; China; Colombia; Comoros; Congo, Dem. Rep. of the; Congo, Rep. of the; Costa Rica; Cote d'Ivoire; Croatia; Cuba; Cyprus; Czech Republic; Denmark; Djibouti; Dominica; Dominican Republic; Ecuador; Egypt; El Salvador; Equatorial Guinea; Eritrea; Estonia; Ethiopia; Fiji; Finland; France; French Guiana; French Polynesia; Gabon; Gambia; Georgia; Germany; Ghana; Greece; Grenada; Guadeloupe; Guatemala; Guinea; Guinea-Bissau; Guyana; Haiti; Honduras; Hong Kong; Hungary; Iceland; India; Indonesia; Iran, Islamic Rep.; Iraq; Ireland; Israel; Italy; Jamaica; Japan; Jordan; Kazakstan; Kenya; Kiribati; Korea, Dem. People's Rep.; Korea, Republic of; Kuwait; Kyrgyzstan; Lao People's Dem. Rep.; Latvia; Lebanon; Lesotho; Liberia; Libyan Arab Jamahiriya; Lithuania; Luxembourg; Macau; Macedonia, The FYR of; Madagascar; Malawi; Malaysia; Maldives; Mali; Malta; Martinique; Mauritania; Mauritius; Mexico; Moldova, Republic of; Monaco; Mongolia; Morocco; Mozambique; Myanmar; Namibia; Nepal; Netherlands; Netherlands Antilles; New Caledonia; New Zealand; Nicaragua; Niger; Nigeria; Norway; Oman; Pakistan; Palau; Panama; Papua New Guinea; Paraguay; Peru; 
Philippines; Poland; Portugal; Puerto Rico; Qatar; Reunion; Romania; Russian Federation; Rwanda; Samoa; San Marino; Sao Tome and Principe; Saudi Arabia; Senegal; Seychelles; Sierra Leone; Singapore; Slovakia; Slovenia; Solomon Islands; Somalia; South Africa; Spain; Sri Lanka; St. Kitts and Nevis; St. Lucia; St. Vincent and the Grenadines; Sudan; Suriname; Swaziland; Sweden; Switzerland; Syrian Arab Republic; Taiwan; Tajikistan; Tanzania; Thailand; Togo; Tonga; Trinidad and Tobago; Tunisia; Turkey; Turkmenistan; Uganda; Ukraine; United Arab Emirates; United Kingdom; United States of America; Uruguay; Uzbekistan; Vanuatu; Venezuela; Viet Nam; Yemen; Yugoslavia; Zambia; Zimbabwe.

The descriptive statistics of the eight countries" panel data on selected variables are reported in Table 3. The results are clear. Specifically, the average size of bilateral trade increased dramatically from 1985 to 1997 . While some data on religious similarity is not available for 1985, for 1997, Brazil, the Democratic Republic of the Congo, France, and the United States have an average value of more than 40 per cent religious similarity with the trade partners included in the study; while China, India, and Japan have an average of less than 10 per cent religious similarity with their trade partners. With regard to the linguistic variable, the mean values of the linguistic similarity scores with respective trade partners increased in Brazil (from 0.006 to 0.019), China (from 0.013 to 0.019), the Democratic Republic of the Congo (from 0.000 to 0.008), France (from 0.029 to 0.064 ), India (from 0.004 to 0.012 ) and the United States (from 0.081 to 0.105 ) over the 1985-1997 period, while the mean value of the linguistic similarity score of Saudi Arabia with its trade partners decreased from 0.018 to 0.010 over the same period.

Table 3

Descriptive statistics for selected variables, 1985 and 1997, by country

\begin{tabular}{|c|c|c|c|c|c|c|c|c|c|c|c|c|}
\hline \multicolumn{7}{|c|}{1985} & \multicolumn{6}{|c|}{1997} \\
\hline \multirow[t]{2}{*}{ Country } & \multirow{2}{*}{$\begin{array}{c}\begin{array}{c}\text { Size of } \\
\text { popu- } \\
\text { lation }\end{array} \\
(\mathbf{m l n} .)\end{array}$} & \multirow{2}{*}{$\begin{array}{c}\text { GNP per } \\
\text { capita } \\
\text { (US\$) }\end{array}$} & \multicolumn{2}{|c|}{$\begin{array}{l}\text { Foreign trade } \\
\text { (bln. US\$) }\end{array}$} & \multicolumn{2}{|c|}{$\begin{array}{l}\text { Mean value of } \\
\text { cultural similarity }\end{array}$} & \multirow{2}{*}{$\begin{array}{c}\begin{array}{c}\text { Size of } \\
\text { popu- } \\
\text { lation }\end{array} \\
(\mathrm{mln} .)\end{array}$} & \multirow{2}{*}{$\begin{array}{c}\text { GNP per } \\
\text { capita } \\
\text { (US\$) }\end{array}$} & \multicolumn{2}{|c|}{$\begin{array}{c}\text { Foreign trade } \\
\text { (bln. US\$) }\end{array}$} & \multicolumn{2}{|c|}{$\begin{array}{c}\text { Mean value } \\
\text { of cultural } \\
\text { similarity }\end{array}$} \\
\hline & & & Export & Import & Language & Religion & & & Export & Import & Language & Religion \\
\hline Brazil & 138.37 & 1941 & 24.49 & 15.64 & 0.006 & 0.437 & 165.16 & 4930 & 51.03 & 65.86 & 0.019 & 0.435 \\
\hline China & $1,054.04$ & 298 & 26.80 & 41.09 & 0.013 & 0.019 & 1255.09 & 745 & 182.89 & 139.26 & 0.019 & 0.058 \\
\hline $\begin{array}{l}\text { Congo, } \\
\text { Dem. }\end{array}$ & 31.67 & 160 & 0.32 & 0.53 & 0.000 & 0.391 & 49.21 & 702 & 1.28 & 0.98 & 0.008 & 0.432 \\
\hline France & 31.67 & 18738 & 87.15 & 96.15 & 0.029 & 0.400 & 58,73 & 23843 & 255.45 & 238.59 & 0.064 & 0.428 \\
\hline India & 781.37 & 291 & 8.03 & 15.42 & 0.004 & 0.062 & 975,77 & 402 & 33.79 & 40.36 & 0.012 & 0.091 \\
\hline Japan & 121.49 & 12850 & 169.07 & 126.32 & 0.000 & 0.027 & 125,92 & 33265 & 392.78 & 325.96 & 0.000 & 0.032 \\
\hline $\begin{array}{l}\text { Saudi } \\
\text { rabia }\end{array}$ & 11.98 & 6953 & 24.82 & 22.46 & 0.083 & 0.222 & 20,21 & 6921 & 59.16 & 27.94 & 0.065 & 0.233 \\
\hline $\begin{array}{l}\text { United } \\
\text { States }\end{array}$ & 241.60 & 17526 & 201.57 & 338.33 & 0.081 & 0.414 & 273,75 & 28789 & 665.68 & 864.13 & 0.105 & 0.426 \\
\hline
\end{tabular}

Notes: (1) GNP per capita and trade are measured at current US dollars; and (2) for foreign trade, only those with the partners (for details for these trade partners, see Annex) included in our panel data are calculated. 


\section{4}

\section{Results of estimation}

Table 4 reports the estimated results of equation 1 for the years 1985 and 1997 respectively. The estimated coefficient on the natural log of DISTANCE is -1.163 for 1985 (statistically significant at the 1 per cent confidence level) and -0.787 for 1997 (statistically significant at the 1 per cent confidence level). In past literature relating to the determinants of international trade (in logarithmic form), statistically significant coefficients on the log of distance have ranged between -0.51 and 1.50 , which demonstrates a percentage decreases in international trade as a result of a 1.0 percent increase in distance 9 .

The estimated coefficient for ADJACENCE is statistically insignificant for international trade in both 1985 and 1997, showing that the eight countries did not have extraordinary trade growth with their neighbouring countries and regions. This is perhaps because, among the panel countries considered in this paper, the US for example has a common land border with only two countries, Canada and Mexico, while China and its neighbouring countries are either separated by geographical barriers ${ }^{10}$ or have not yet set up efficient economic and trade relations (such as with Afghanistan and North Korea, two autocratic economies). However, Table 4 does show growth in the contribution of ADJACENCE to bilateral trade between 1985 and 1997, especially after taking "import" into account (note that the estimated coefficient on ADJACENCE, 1.426, is statistically significant at 1 percent in 1985, compared to the insignificant estimated coefficient of 0.705 in 1997).

Table 4

The regressions for trade, 1985 and 1997

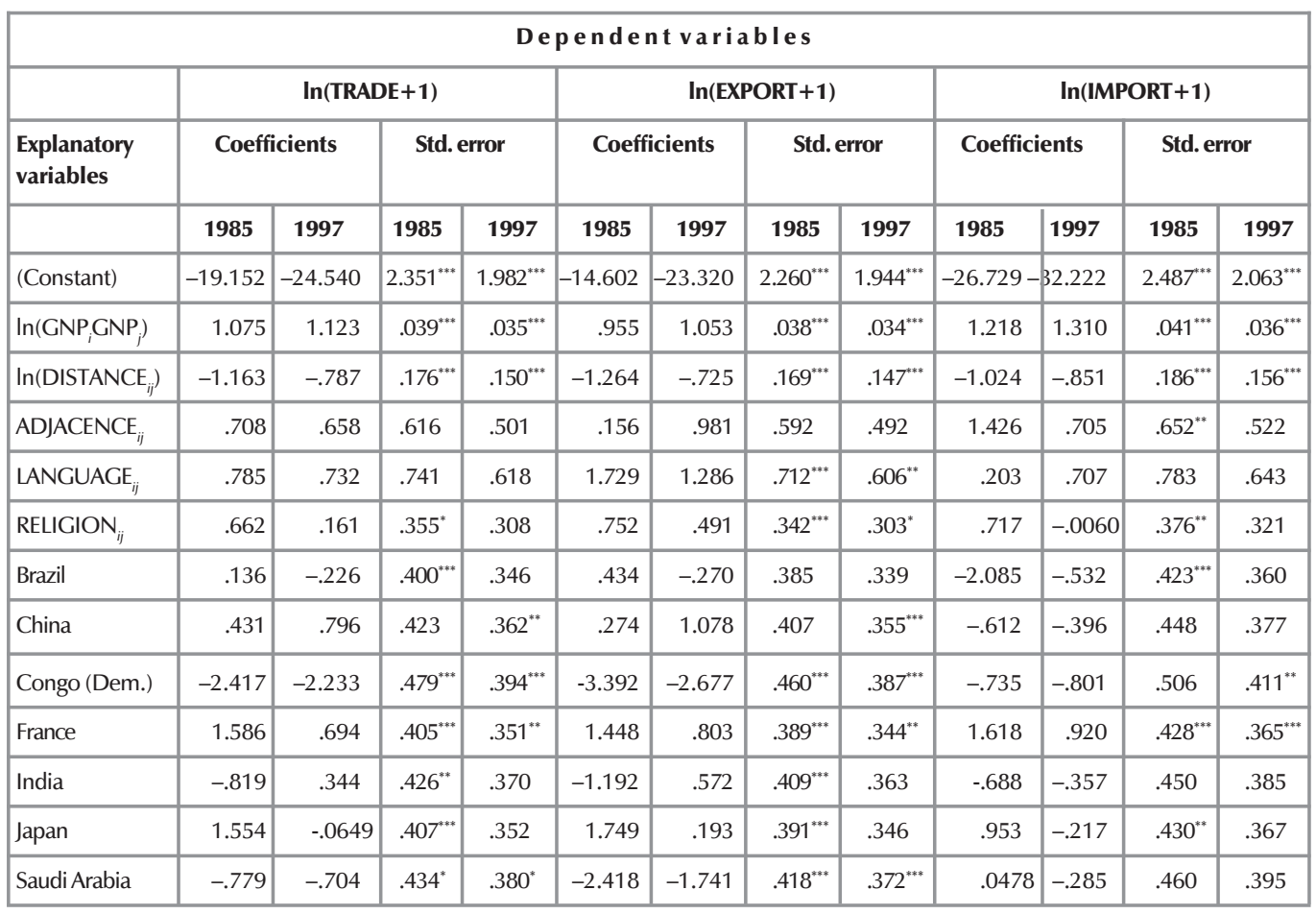




\begin{tabular}{|l|cccccc|}
\hline $\begin{array}{l}\text { Coeff. of } \\
\text { correlation } \\
\left(R^{2}\right)\end{array}$ & $0.598(1985)$ & $0.569(1997)$ & $0.617(1985)$ & $0.582(1997)$ & $0.581(1985)$ & $0.584(1997)$ \\
\hline $\begin{array}{l}\text { F-statistical } \\
\text { value }\end{array}$ & $156.3(1985)$ & $170.1(1997)$ & $169.0(1985)$ & $179.0(1997)$ & $145.5(1985)$ & $180.9(1997)$ \\
\hline $\begin{array}{l}\text { Sig. of the } \\
\text { regression }\end{array}$ & 0.000 & 0.000 & 0.000 \\
\hline $\begin{array}{l}\text { Number of } \\
\text { observations }\end{array}$ & $1296(1985)$ & $1568(1997)$ & $1296(1985)$ & $1568(1997)$ & $1296(1985)$ & $1568(1997)$ \\
\hline
\end{tabular}

Note: In what follows, ${ }^{* * * * *}$, and *denote statistically significant at greater than 1 percent and 5 percent levels respectively.

Regarding cultural influences on international trade, this study questions the hypothesis that ideological similarities were emphasized in international relations during the Cold-War period (see, for example, Huntington, 1996). The estimated coefficient for LANGUAGE is statistically insignificant in both 1985 and 1997; it is, however, statistically significant for "export" in both 1985 and 1997. These results show that from 1985 to 1997 "export" was influenced by the linguistic factors more than “import'. The estimated coefficient on RELIGION is significant in 1985 but not in 1997, which does not imply an increasing role of religious factors in international trade.

It seems that for the year 1997 the partial relation between $\ln (\mathrm{TRADE}+1)$ and LANGUAGE follows a linear pattern (see Figure 1a) but the relation between $\ln ($ TRADE +1 ) and RELIGION does not (see Figure 1b). Does this mean that international trade was no longer influenced by religious similarity in 1997 ?

\section{Figure 1}

The partial correlations between trade and cultural similarities

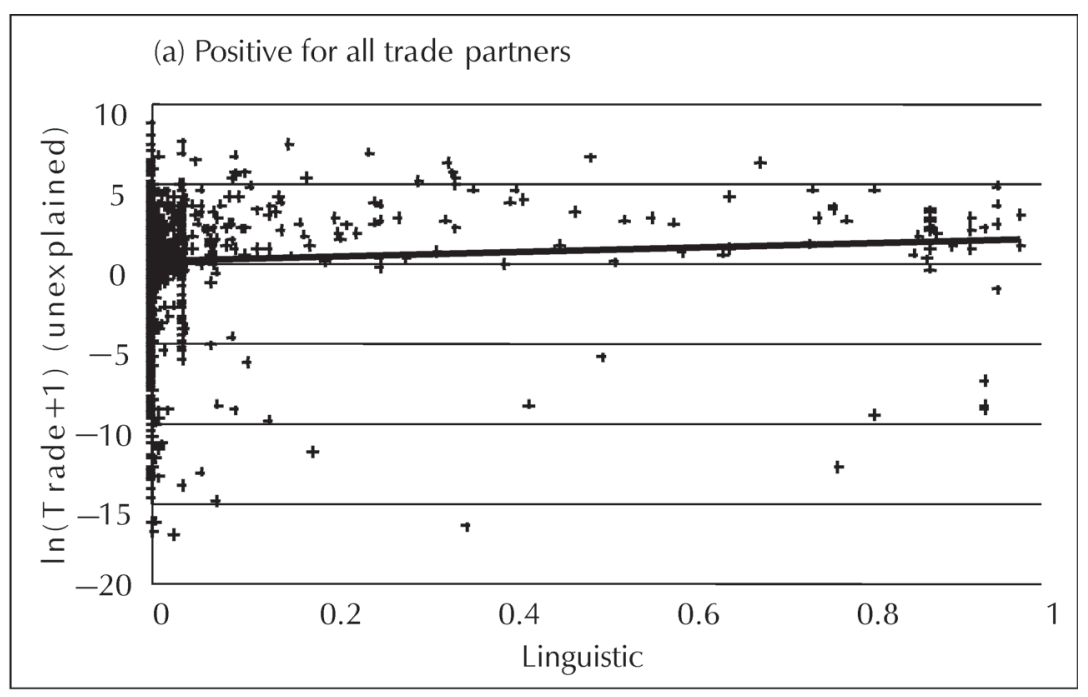




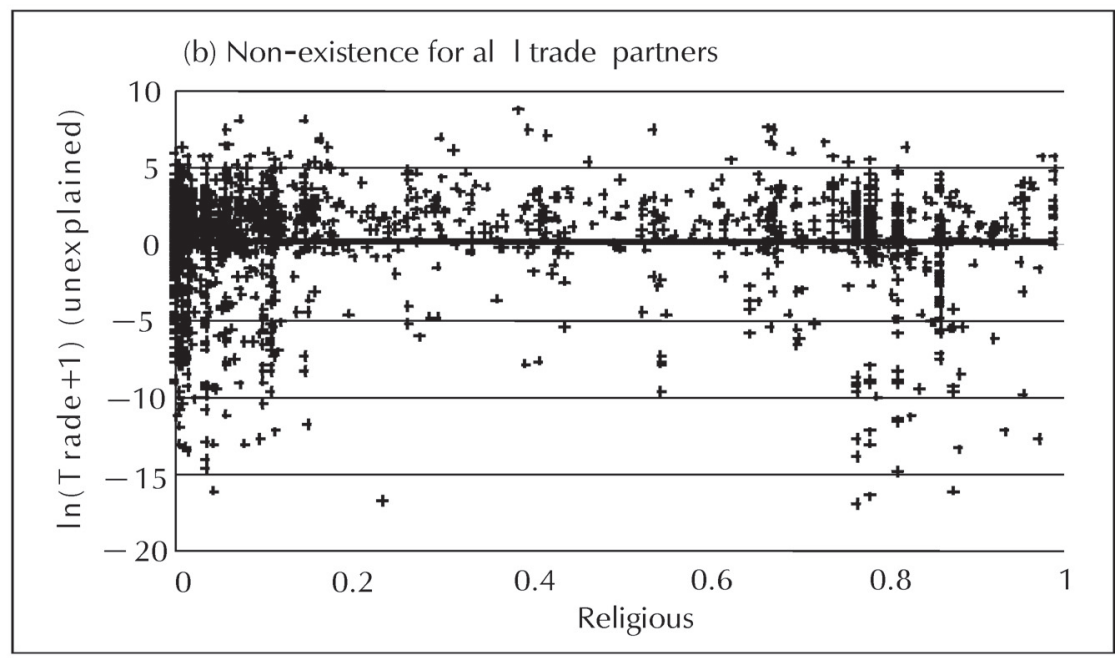

To investigate the possible non-linear relationship between RELIGION and international trade, we employ equation 3 . The estimated coefficients are jointly significant for RELIGION and GNPPC and also individually significant for RELIGION in 1997 (the estimated results are reported in Table 5). Specifically, the estimated relation implies that the effect of religious influence on trade is positive for values of per capita GNP below US\$3767 (or US\$5273 for “export" and
US\$3180 for "import') and then becomes negative ${ }^{11}$. Quantitatively, the estimated marginal effect of the RELIGION score on trade ranges from a high of 4.210 (or 4.536 for "export" and 3.245 for "import') for the poorest country (Republic of Congo, with a per capita GNP of US\$52 in 1997) to a low of -2.266 (or -1.934 for "export" and -1.953 for "import') for the richest country (Luxemburg, with a per capita GNP of US\$37,785 in 1997).

Table 5

The linguistic and religious influences on trade, 1997

\begin{tabular}{|l|c|c|c|c|c|c|}
\hline \multicolumn{7}{|c|}{ D e p e n d e n t v a r i a b I e s } \\
\hline & \multicolumn{2}{|c|}{ In(TRADE+1) } & \multicolumn{2}{c|}{ In(EXPORT+1) } & \multicolumn{2}{c|}{ In(IMPORT+1) } \\
\hline Explanatory variables & Coefficients & Std. error & Coefficients & Std. error & Coefficients & Std. error \\
\hline$($ Constant) & -28.534 & $2.017^{* * *}$ & -27.310 & $1.978^{* * *}$ & -35.428 & $2.116^{* * *}$ \\
\hline $\ln \left(\mathrm{GNP}_{i} \mathrm{GNP}_{j}\right)$ & 1.217 & $.036^{* * *}$ & 1.147 & $.035^{* * *}$ & 1.385 & $.038^{* * *}$ \\
\hline $\ln \left(\mathrm{DISTANCE}_{i j}\right)$ & -.755 & $.147^{* * *}$ & -.693 & $.144^{* * *}$ & -.826 & $.154^{* * *}$ \\
\hline ADJACENCE $_{i j}$ & .568 & .493 & .891 & $.483^{*}$ & .632 & .517 \\
\hline LANGUAGE $_{i j}$ & 1.129 & $.609^{*}$ & 1.683 & $.598^{* * *}$ & 1.025 & $.639^{*}$ \\
\hline RELIGION $_{i j}$ & 8.094 & $1.094^{* * *}$ & 8.416 & $1.072^{* * *}$ & 6.363 & $1.147^{* * *}$ \\
\hline RELIOGION $_{i j}{ }^{*} \ln \left(\mathrm{GNPPC}_{j}\right)$ & -.983 & $.130^{* * *}$ & -.982 & $.128^{* * *}$ & -.789 & $.137^{* * *}$ \\
\hline Brazil & .0611 & .342 & .0169 & .335 & -.302 & .358 \\
\hline China $^{*}$ & 1.023 & $.357^{* * *}$ & 1.305 & $.350^{* * *}$ & -.214 & .374 \\
\hline
\end{tabular}




\begin{tabular}{|l|c|r|r|r|r|c|}
\hline Congo (Dem.) & -1.629 & $.396^{* * *}$ & -2.074 & $.388^{* * *}$ & -.316 & .415 \\
\hline France & .888 & $.345^{* * *}$ & .996 & $.339^{* * *}$ & 1.076 & $.362^{* * *}$ \\
\hline India & .603 & $.365^{*}$ & .831 & $.358^{* * *}$ & -.149 & .383 \\
\hline Japan & .00774 & .346 & .265 & .340 & -.159 & .363 \\
\hline Saudi Arabia & -.548 & .374 & -1.585 & $.366^{* * *}$ & -.159 & .392 \\
\hline Coeff. of correlation $\left(\mathrm{R}^{2}\right)$ & 0.584 & 0.597 & 0.593 & & & \\
\hline F-statistical value & 167.1 & 176.0 & 173.1 & & & \\
\hline Sig. of the regression & 0.000 & 0.000 & 0.000 & & & \\
\hline Number of observations & 1568 & 1568 & 1568 & & & \\
\hline
\end{tabular}

Note: The variable RELIOGION*In(GNPPC) is the product of RELIGION scores and the natural log of per capita GNP (GNPPC).

To verify these results, the trade model was reestimated with the RELIGION scores as two separate coefficients, as illustrated in equation 4. One coefficient applies for values of per capita GNP below US\$3767 (or US\$5273 for “export” and US\$3180 for “import'), the break points estimated above, and the other for values of per capita GNP above these break points. The results, as shown in Table 6, are estimated coefficients for RELIGION are 1.388 (or 1.617 for "export" and 0.896 for "import') in the low ranges of per capita GNP and -1.293 (or -1.323 for "export" and -1.192 for "import') in the high ranges. These estimated values are statistically significant at a greater than 1 percent confidence level. Thus, this piecewise-linear form tells us a similar story to that found in the estimation that includes the interaction between the RELIGION score and the natural $\log$ of per capita GNP in Table 5. Moreover, the absolute values of these estimated coefficients show that, although import is slightly more sensitive to religious similarity with lower income partners than with higher income partners, "export" and "export plus import" are more sensitive to religious similarity with higher income partners than with lower income partners.

\section{Table 6}

How religious influences on trade differ between low- and high-income partners, 1997

\begin{tabular}{|c|c|c|c|c|c|c|}
\hline \multirow[b]{3}{*}{ Explanatory variables } & \multicolumn{4}{|c|}{ Dependent variables } & & \\
\hline & \multicolumn{2}{|c|}{$\ln ($ TRADE + 1) } & \multicolumn{2}{|c|}{ In(EXPORT+1) } & \multicolumn{2}{|c|}{ In(IMPORT + 1) } \\
\hline & Coefficients & Std. error & Coefficients & Std. error & Coefficients & Std. error \\
\hline (Constant) & -26.974 & $1.988^{* * *}$ & -25.705 & $1.938^{* * *}$ & -34.208 & $2.081^{* * *}$ \\
\hline $\ln \left(G_{N} P_{i} G N P_{j}\right)$ & 1.185 & $.035^{* * *}$ & 1.108 & $.034^{* * *}$ & 1.360 & $.037^{* * *}$ \\
\hline $\ln \left(\right.$ DISTANCE $\left._{i j}\right)$ & -.787 & $.147^{* * *}$ & -.704 & $.144^{* * *}$ & -.852 & $.154^{* * *}$ \\
\hline ADJACENCE $_{i j}$ & .586 & .494 & 1.016 & $.483^{* *}$ & .646 & .518 \\
\hline LANGUAGE $_{i j}$ & 1.112 & $.612^{*}$ & 1.775 & $.600^{* * *}$ & 1.017 & .641 \\
\hline RELIGION $_{i j}\left(\right.$ high GNPPC ) $^{2}$ & -1.293 & $.373^{* * *}$ & -1.323 & $.385^{* * *}$ & -1.192 & $.391^{* * *}$ \\
\hline RELIGION $_{i j}($ low GNPPC $)$ & 1.388 & $.355^{* * *}$ & 1.617 & $.334^{* * *}$ & .996 & $.372^{* * *}$ \\
\hline Brazil & -.0370 & .342 & -.0770 & .334 & -.378 & .358 \\
\hline China & .946 & $.358^{* * *}$ & 1.229 & $.350^{* * *}$ & -.273 & .374 \\
\hline Congo (Dem.) & -1.827 & $.394^{* * *}$ & -2.293 & $.384^{* * *}$ & -.470 & .412 \\
\hline France & .815 & $.346^{* * *}$ & .927 & $.339^{* * *}$ & 1.019 & $.362^{* * *}$ \\
\hline
\end{tabular}




\begin{tabular}{|l|c|c|c|c|c|c|}
\hline India & .511 & .365 & .741 & $.357^{* *}$ & -.221 & .382 \\
\hline Japan & -.0917 & .348 & .267 & .340 & -.172 & .364 \\
\hline Saudi Arabia & -.592 & .375 & -1.626 & $.366^{* * *}$ & -.193 & .392 \\
\hline Coeff. of correlation $\left(\mathrm{R}^{2}\right)$ & 0.581 & & 0.596 & & 0.591 & \\
\hline F-statistical value & 165.0 & & 175.3 & & 172.0 & \\
\hline Sig. of the regression & 0.000 & & 0.000 & & 0.000 & \\
\hline Number of observations & 1568 & & 1568 & & 1568 & \\
\hline
\end{tabular}

Note: The system with RELIGION (low GNPPC) and RELIGION (high GNPPC) allows for two separate coefficients on the religion variable. The first coefficient applies when GNPPC is below the break point for a negative effect of RELIGION score on the dependent variable, as implied by the system that includes RELIGION and RELIGION*In(GNPPC) in Table 4. The second coefficient applies for higher values of GNPPC.

Figure 2 shows the partial relation between the log of TRADE and the RELIGION scores for the low and high ranges of per capita GNP. In Figure 2a, where per capita GNP is below US $\$ 3767$, the estimated relation is positive. In Figure $2 b$, where per capita GNP is above US $\$ 3767$, the estimated relation is negative. A possible interpretation of these results involves the ideas that, although further evidence from both theoretical and empirical sides is still needed, cultural dissimilarity brings about comparative advantages for industrial production and consumption. While the comparative advantages exist between all culturally dissimilar economies, the cost of intercultural transactions is usually high in lowincome nations and low in high-income nations. This, as a result, tends to retard trade in poor economies and to encourage trade in richer places.

Figure 2

The partial correlations between trade and religious similarity

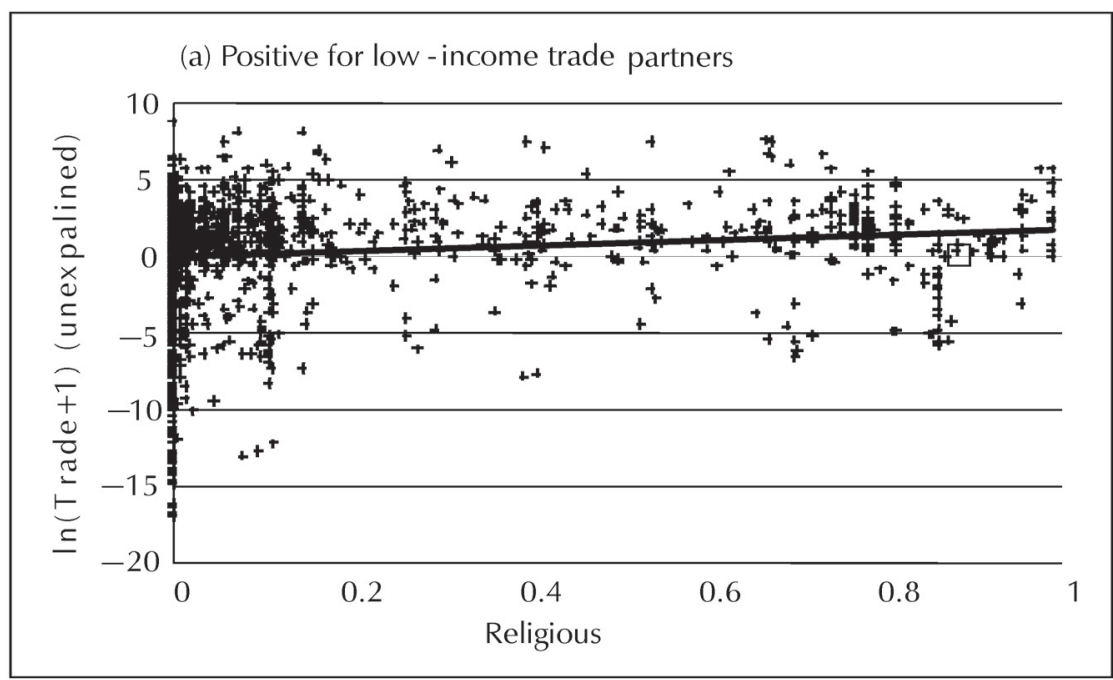




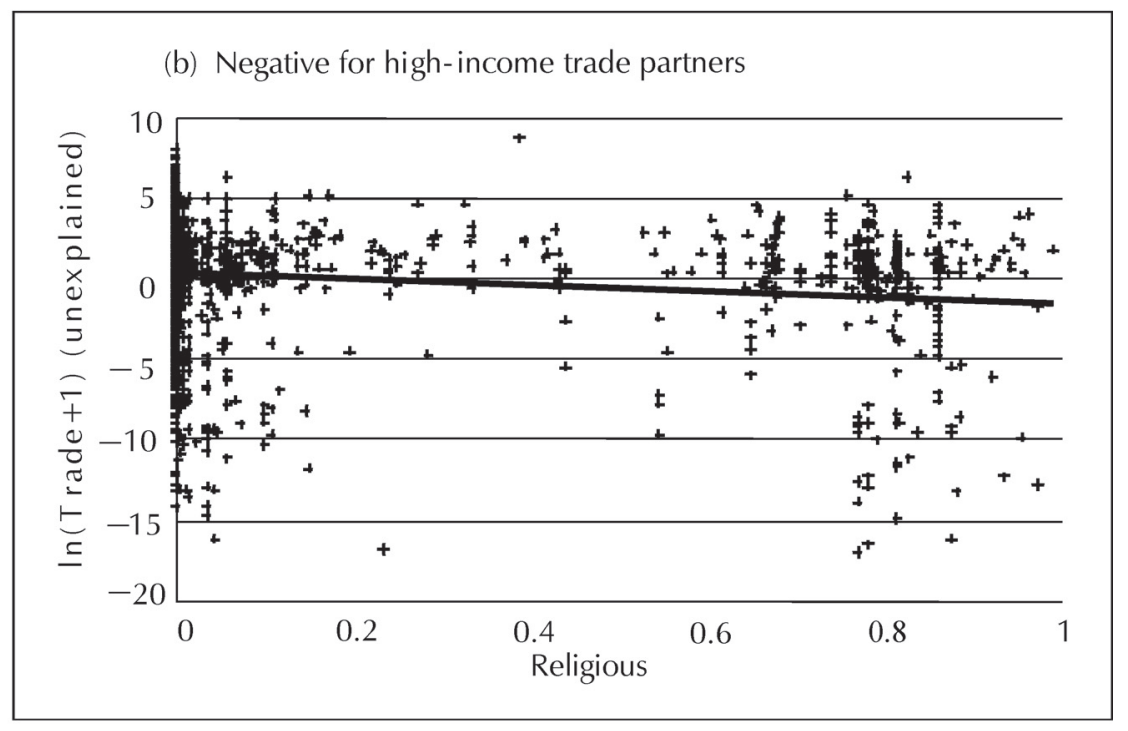

The economic determinants of trade are a controversial issue in many existing studies. For example, according to the Heckscher-Ohlin Theorem (see Heckscher, 1919 and Ohlin, 1933), countries with dissimilar per capita incomes will trade more than countries with similar incomes. However, a number of empirical results indicate that if the distribution of national incomes across countries becomes more equal over time, the volume of trade should increase ${ }^{12}$. Moreover, Helpman (1987) and Krugman (1995) predict that the sum of the logs of per capita GNPs for two countries will have a positive effect on the log form of trade between the two countries.

To present evidence to illustrate trade dynamics with respect to income level, let us again use the estimated coefficients in Table 5.

The first-order differentials of $\ln \left(\mathrm{TRADE}_{i j}+1\right), \quad \ln \left(\mathrm{EXPORT}_{i j}+1\right)$ and $\ln \left(\mathrm{IMPORT}_{i j}+1\right)$ with respect to $\operatorname{lnGNPPC}_{j}$ can be treated as approximate measures of the elasticities of TRADE, EXPORT and IMPORT on per capita GNP respectively. The sum of the estimated coefficients for $\ln \left(\mathrm{GNP}_{i j} \mathrm{GNP}_{i j}\right)$ and RELIGION*In $\left(\mathrm{GNPPC}_{j}\right)$ also approximately reflect the elasticities of trade. As indicated by Table 5, the elasticities of TRADE, EXPORT and IMPORT with respect to GNPPC become
1.217-0.983*RELIGION,

$1.147-$ $0.982 *$ RELIGION and 1.385-0.789* RELIGION respectively ${ }^{13}$. Obviously, since RELIGION ranges between 0 and 1 , international trade in the eight countries selected in this study is always elastic to the income levels of their trade partners. In other words, for all the trade partners, increasing the level of per capita GNP will increase the international trade under all circumstances. In fact, if the estimated results based on this panel data are taken as representative of the rest of the world, they provide evidence supporting the view that international trade is more elastic to income level in religiously heterogeneous countries and regions than in religiously homogeneous places.

\section{5}

\section{Conclusion}

Many current trade theories seem incomplete and sometimes controversial, especially when trade partners with different cultural characteristics are studied. For example, many models cannot satisfactorily explain why economic activity in the same or similar cultural environments has become increasingly more important than that in a cross-cultural environment since the 1980s; neither can they 
provide a clear and concrete methodology for us to understand the extraordinary trade performances within the Chinese cultural circle (Taiwan, Hong Kong, Macau, Mainland China, and other Chinese areas) for the post-Cold War period.

This paper therefore sets out to investigate the determinants of international trade. Though economists have shown a growing concern with the role of culture in international economic analysis, few studies have dealt quantitatively with the effects of various cultural factors. Using a gravity model of trade and panel data for eight countries, we have presented an interpretation of the significance of cultural influences on international trade. The estimated results indicate that cultural influences on international trade are significant. This could be supported by the fact that transportation costs have declined over the past century and also by the increasing role of culture factors in international economic activities during the post-Cold War period. If our estimated results are correct, cultural influences on international trade have not become greater between the mid1980s and mid-1990s. Linguistic influence on trade is found to be significant for export but not for import in both 1985 and 1997. The adoption of a common standard by different cultural groups is not recommended, since such groups have markedly differing attitudes as well as different cultural values. The larger the number of cultural groups involved in a multicultural society, the higher the managerial risks and costs resulting from diversity. However, "cultural dissimilarity" results in increased cost of intercultural transactions, but also generates "economic complementarity" among the trading economies. Both of these factors influence trade. Our empirical results suggest that high-income trade partners will be less sensitive to cultural dissimilarity than developing countries in which cultural dissimilarity tends to produce barriers to international trade. This postulated relation shows that the coefficient of religious influence on trade is positive for values of per capita GNP below a breakpoint and then becomes negative. Our estimated coefficients also show that the cultural influence on international trade differs between import and export. Specifically, for low-income trade partners, religious dissimilarity retards import more than export; by contrast, for high-income trade partners, it encourages export more than import.

We have also found that the elasticity of bilateral trade for various income levels is larger for culturally heterogeneous partners than for homogeneous ones. If this result is correct, a best policy option can be deduced. The finding shows that "diversity of cultures" can act as a source of creativity and potential profitability in bilateral trade. Therefore, policy makers must provide their country's people with their unique cultures different from trade partners, while emphasizing to broaden their knowledge, to discover the world in its imposing diversity, and also allowing all individuals to lead a life that is decent, dignified and wise, without losing their identity and sense of community, and without betraying their heritage (WCCD, 1995).

Consequently, native languages are beginning to be re-evaluated, traditional knowledge rediscovered and local economies revitalized. In fact, a world without the "other" would be a world of stagnation, for, in culture as in nature, diversity holds the potential for innovation and creative, non-linear solutions (Shanker, 1996).

Lastly, we must mention that the data on linguistic and religious groups are not as accurate as the economic and geographical indicators used in this paper. For example, since some countries collect data on ethnic or "national" groups only, ethnic distribution often has to be assumed as conforming roughly to the distribution of language communications. However, this approach should be viewed with caution, because a minority population is not always free to educate its children in its own languages and because better economic opportunities often draw minority group members into the majority-language communities (Britannica Book, 1998). It should be noted that data on religious groups are even more unreliable for the year 1985. As pointed out by Britannica Book, until 1989 communist countries had consciously attempted to ignore, suppress or render invisible the religious practice within their borders (1998). 
Nevertheless, the treatment of linguistic and religious factors as continuous variables in this paper is an improvement on the past studies in which language was treated as a dummy variable and religion was omitted. However, due to the unavailability of complete time series data sets on cultural variables, this paper is only based on the panel data for two years, 1985 and 1997, and eight countries. In the future, the estimation of cultural influences on international trade could involve investigation of data from longer periods of time and wider panels.

\section{Acknowledgements}

The general idea of this paper was presented in a seminar at Institute of Economics, Chinese Academy of Social Sciences (CASS) (Beijing, Nov. 1999) and at the Fourth Annual Global Development Conference (Cairo, Egypt, January 19-21, 2003). We gratefully acknowledge Professors Li Shi of the CASS (China) and Shujiro Urata of Waseda University (Japan), and two anonymous referees for their comments and suggestions on the various versions of the paper. Thanks are also due to Ms. Wang Huayan, Mr. Guo Liqing and Mr. Xing Youqiang for their excellent assistance on the research. All remaining errors are the authors" sole responsibilities.

\section{Endnotes}

1 Not all studies are this simplistic; Boisso and Ferrantino (1997) for example construct a continuous scale for measuring linguistic distance.

2 The number of country pairs in these studies is thus $63 \times(63-1) \div 2=1953$.

3 Since the largest number of economies for which we have been able to assemble data on the variables employed is 198 , the number of country (region) pairs now becomes $198 \times(198-1) \div 2=$ 19503. It seems impossible for us to collect all the cross-national data on the linguistic and religious groups of each country (region).

4 The application of the gravity model in regional science and economic geography can be traced back to as far as the 1940s (see, for example,
Zipf, 1946; Stewart, 1948 and Isard, 1949).

5 The idea of including this kind of interactions is taken from Barro (2000).

6 Since Germany and Russia, two major players in the world economy, experienced territorial changes during the 1985-1997 period, we excluded these two countries from the analysis.

7 In the Britannica Book (1998), atheism and nonreligion are each treated as a "religious affiliation" in USA and China, but in other countries such as Austria, Czech Republic, North Korea, etc., they are grouped as a single religious group.

8 The panel data on the linguistic and religious similarity scores are available from the authors upon request.

9 Specifically, Linnemann (1966) estimates the coefficient as -0.77 , Brada and Mendez (1983) and Oguledo and MacPhee (1994) as 0.76, Bikker (1987) as -0.90 to -1.1 , and Mansfield and Bronson (1997) as -0.51 to -0.69 (for 1950 1990).

10 Such as the mountains of Altai with Russia and Mongolia, Tian-Shan with Kazakhstan and Kyrgyzstan, and Himalayas with Bhutan, India and Nepal, and so on.

11 The three breakpoint values are obtained by letting the first-order differentials of the dependent variables $\left(\ln \left(\mathrm{TRADE}_{i j}+1\right)\right.$, $\ln \left(\mathrm{EXPORT}_{i j}+1\right)$ and $\left.\ln \left(\mathrm{IMPORT}_{i j}+1\right)\right)$ with respect to RELIGION be zero.

12 For example, Linder (1961) predicts that countries with similar levels of per capita income will tend to have similar preferences with somewhat differentiated marketable goods, and thus will trade more with each other.

13 Before being differentiated to yield its first-order partial differential with respective to $\ln \left(\mathrm{GNPPC}_{j}\right)$, the variable $\ln \left(\mathrm{GNP}_{i} \mathrm{GNP}_{j}\right)$ can be decomposed into $\ln \left(\mathrm{POP}_{i} \mathrm{POP}_{j}\right)+\ln \left(\mathrm{GNPPC}_{i}\right)+\ln \left(\mathrm{GNPPC}_{j}\right)$, where $\mathrm{POP}_{i}$ and $\mathrm{POP}_{j}$ are the sizes of population of countries $i$ and $j$ respectively.

\section{References}

1 BARRO, J.R. (2000) "Inequality and growth in a panel of countries," Journal of Economic Growth, 5: 5-32.

2 BIKKER, J. (1987) "An international trade flow model with substitution: an extension of the gravity model," Kyklos, 40: 315-337.

3 BOISSO, D, \& FERRANTINO, M. (1997) "Economic distance, cultural distance and openness in international trade: empirical 
puzzles," Journal of Economic Integration, 12: 456-484.

4 BRADA, J. \& MENDEZ, J. (1983) "Regional economic integration and the volume of intraregional trade: a comparison of developed and developing country experience," Kyklos, 36: 589603.

5 BRITANNICA BOOK OF THE YEAR (1986) Encyclopedia Britannica: Chicago.

6 BRITTANICA BOOK OF THE YEAR (1998) Encyclopedia Britannica: Chicago.

7 DEARDORFF, A. (1997) "Determinants of bilateral trade: does gravity work in a classical world?" In The Regionalization of the World Economy. Frankel, J. (ed.) University of Chicago Press: Chicago.

8 EICHENGREEN, B.; FRIEDEN, F. \& VON HAGEN, J. (eds.) (1995) Monetary and Fiscal Policy in an Integrated Europe, Springer-Verlag: New York.

9 FOROUTAN, F. \& PRITCHETT, L. (1993) "Intra-sub-Saharan African trade: is it too little?" Journal of African Economics, 2: 74-105.

10 FRANKEL, J (ed.) (1997) The Regionalization of the World Economy, University of Chicago Press: Chicago.

11 FRANKEL, J. \& WEI, S. (1995) "European integration and the regionalization of world trade and currencies: the economics and the politics," In Monetary and Fiscal Policy in an Integrated Europe, Eichengreen, Frieden, and Von Hagen (eds.) Springer-Verlag: New York.

12 FRANKEL, J.; ROMER, D. \& CYRUS, T. (1995) "Trade and growth in East Asian countries: cause and effect?" Pacific Basin Working Paper Series No. 95-03, Federal Reserve Bank of San Francisco: San Francisco.

13 FRANKEL, J.; STEIN, E. \& WEI, S. (1994) "Trading blocs: the natural, the unnatural, and the super-natural," Center for International and Development Economics Research (CIDER) Working Paper No. C94-034, University of California: Berkeley.

14 FRANKEL, J.; STEIN, E. \& WEI, S. (1997) Regional Trading Blocs in the World Economic System Institute for International Economics: Washington, DC.

15 GUO, R. (2004) "How culture influences on foreign trade: evidence from the US and China," The Journal of Socio-Economics, Forthcoming.

16 GUO, R. \& HWANG, E.G. (2002) "Cultural diversity and economic development in a panel of nations: evidence from the 1982-1997 data," Review of International Studies, 5(1), 25-48.
17 HAVRYLYSHYN, O. \& PRITCHETT, L. (1991) "European trade patterns after the transition," Policy, Research and External Affairs Working Paper Series No. 74, World Bank: Washington, DC.

18 HECKSCHER, E.F. (1919) "The effect of foreign trade on the distribution of income," Ekonomisk Tidskirift, 497-512.

19 HELPMAN, E. (1987) "Imperfect competition and international trade: Evidence from fourteen industrial countries," Journal of the Japanese and International Economies, 1: 62-81.

20 HUNTINGTON, S.P. (1996) The Clash of Civilization and the Remaking of World Order, Simon \& Schuster: New York.

21 IMF (2003) Direction of Trade Statistics, IMF: Washington DC.

22 ISARD, W. (1949; 1990): "Gravity, potential, and spatial interaction models," In Practical Methods of Regional Science and Empirical Applications: Selected Papers of Walter Isard: Volume 2. Smith, C. (ed.) New York University Press: New York.

23 KRUGMAN, P.R. (1995) "Growing world trade: causes and consequences," Brookings Papers on Economic Activity, 1: 327-62.

24 LINDER, S.B. (1961) An Essay on Trade and Transformation, New York: John Wiley and Sons.

25 LINNEMANN, H. (1966) An Econometric Study of International Trade Theory, North-Holland: Amsterdam.

26 MANSFIELD, E. \& MILNER, H. (eds.) (1997) The Political Economy of Regionalism, Columbia University Press: New York.

27 MANSFIELD, E. \& BRONSON, R. (1997) "The political economy of major-power trade flows," In The Political Economy of Regionalism, Mansfield, E. \& Milner, H. (eds.) Columbia University Press: New York.

28 MARKUSEN, J. (1986) "Explaining the volume of trade: An eclectic approach," American Economic Review, 76: 1002-11.

29 OGULEDO, V. \& MACPHEE, C. (1994) "Gravity models: A reformulation and an application to discriminatory trade arrangement," Applied Economics, 26: 107-20.

30 OHLIN, B. (1933) Interregional and International Trade, Harvard University Press: Cambridge, MA.

31 PÖYHÖNEN, P. (1963) "A tentative model for the volume of trade between countries," Weltwirtschaftliches Archiv, 90(1): 93-9. 
32 RAUCH, J.E. (1999) "Networks versus markets in international trade," Journal of International Economics, 48: 7-35.

33 SHANKER, R. (1996) Diversity and Development, International Development Information Center: Québec.

34 SMITH, C. (ed.) (1990) Practical Methods of Regional Science and Empirical Applications: Selected Papers of Walter Isard: Volume 2, New York University Press: New York.

35 STEWART, J.Q. (1948) "Demographic gravitation: evidence and applications," Sociometry, 2: 31-58.

36 TINBERGEN, J. (1962) "An analysis of world trade flows, the Linder Hypothesis, and exchange risk," In Shaping the World Economy, Tinbergen, J. (ed.) The Twentieth Century Fund: New York.

37 TINBERGEN, J (ed.) (1962) Shaping the World Economy, New York: The Twentieth Century Fund.
38 UN. (1986) Annual Statistical Yearbook, UN: New York.

39 WCCD (1995) Our Cultural Diversity, Paris: World Commission for Culture and Development.

40 WORLD ATLAS (1994) Rand McNally: New York.

41 WORLD BANK (1986) World Bank Atlas, World Bank: Washington DC.

42 WORLD BANK (1999) World Development Indicators CD-ROM, World Bank: Washington DC.

43 ZIPF, G.K. (1946) "The $\mathrm{P}^{1} \mathrm{P}^{2} / \mathrm{D}$ Hypothesis: on the intercity movement of persons," American Sociological Review, 11(6): 677-686. 